\title{
Effects of The Home Physical Therapy on Recovery of Muscle Strength and Gait for Discharged Patients Who Underwent Total Knee Replacement
}

\begin{abstract}
This study aims to identify the effect of home physical therapy on patients who left the hospital after total knee arthroplasty, compared to the Daily living group, when it was applied to them, under the guidance of physical therapists. As research subjects, 20 patients that were scheduled to leave the hospital after unilateral total knee arthroplasty, were chosen, and they were randomly divided into a home physical therapy group(10 patients) and an Daily living group(10 patients) in order to conduct an experiment. During the 4-week research, home physical therapy was offered for 40 mins once for 5 days a week, and muscular strength, gait components were measured. For muscular strength, quadriceps muscle strength, hamstring muscle strength were measured, and as gait components, endurance, speed, step time, single-limb support were analysed.

For this experiment, pre- and post-measurement were performed, and collected data were analyzed using SPSS ver. 18.0 statistical program. From the analysis of data, the following study results were obtained.

Home physical therapy group and Daily living group both showed significant improvements in quadriceps muscle strength, hamstring muscle strength, and quadriceps muscle strength, hamstring muscle strength of home physical therapy group more significantly improved than Daily living group's.

In relation to gait components, gait endurance, gait speed, step time significantly improved in both of home physical therapy group and Daily living group, whereas home physical therapy group only showed significant improvements in single-limp support. According to the comparison between two groups, gait speed, single-limp support and step time improved more significantly in the home physical therapy group than in the Daily living group.

In conclusion, positive results were revealed in both home physical therapy group and Daily living group, with regard to muscular recovery of lower limbs of patients discharged from the hospital after total knee arthroplasty and walking, but considering the comparison results between two groups, it seems that applying home physical therapy is more effective than maintaining a daily life.
\end{abstract}

Key words: Total Knee Replacement(TKR); home physical therapy; gait
Yong Su Janga, Moo Ki Kimb, Ji Sung $\mathrm{Kim}^{\mathrm{c}}$, Ja Pung $\mathrm{KoO}^{\mathrm{b}}$, Si Eun Park ${ }^{\mathrm{d}}$, Wan Suk Choie, Bo Kyoung $\mathrm{Kim}^{\mathrm{e}}$, Yong Youn Kim', Soon Hee $\mathrm{Kim}^{9}$

aRusk Bundang Hospital, Seongnam; 'Pohang College, Pohang; 'Suwon Women's College, Suwon; 'Yongin University, Yongin; 'International University of Korea, Jinju; 'OK savings bank rush \& cash pro-volleyball club, Ansan; ${ }^{\circ}$ Yongin University, Yongin, korea

Received : 06 May 2014

Revised : 28 July 2014

Accepted : 20 September 2014

Address for correspondence

Soon Hee Kim, PT, Ph.D

Department of Physical Therapy, Yongin University, 470 Samga-dong, Cheoingu, Yongin, Korea

Tel: 82-31-8020-2774

E-mail: shkim@yongin.ac.kr

\section{INTRODUCTION}

The increase and aging of elderly population have played a leading role in the growing in chronic diseases(1). Among the chronic diseases, degenerative arthritis reached $38.1 \%$ of prevalence in the elderly population over 65 . Female showed a higher preva- lence than male. The prevalence grew higher as age increased(2).

For degenerative arthritis, the highest incidence site is known to be the knee joint(3). This degenerative knee arthritis can have a significant impact on activities of daily living and gait ability(4).

If the conventional therapy has limits in the process 
of treatment of osteoarthritis, total knee replacement (TKR) may be practiced instead(5).

Recently, Health Insurance Review and Assessment Service analyzed the number of surgeries in Korea from 2006 to 2011. According to the data, the number of TKR surgeries reached 30,777 cases in 2006 and 51,050 cases in 2011, $65.9 \%$ increase in 7 years $(6)$.

TKR effectively relieves pains in the knee joint, but causes weakening, voluntary contraction, and crosssectional area reduction of quadriceps femoris muscle $(7,8)$. Another study reported that TKR may leave hamstring muscle postoperatively dysfunctional, which similarly may goes for quadriceps femoris muscle(9). Strengthening exercises around the artificial joint surgery is very important to restore the normal knee joint function. Thus, enhanced quadratus femoris and hamstring muscles absorb the shock of joints of the femoral, tibial bone, and provide functional stability to the bone $(10,11)$.

Among various approaches to resistance exercises for muscle strengthening, an elastic band is very easy to practice. Additionally, the elastic band is safe and economic, highly useful as an effective tool, and can be used very simply(12).

TKR patients need to be admitted usually for 16-60 days during the recovery period or until the suture is removed(13). But during the inpatient rehabilitation period after TKR, the fee for the remaining movement therapy except for physical therapy spent is usually paid by uninsured medical expenses(14). It has been thus reported that for the elderly, if they have not subscribed to private insurance, medical costs highly increase(15).

In addition, currently, most hospitals, providing rehabilitation services after surgery, have decided inpatient rehabilitation period into about 3-4 weeks due to their circumstances. Thus, the period is may not be enough for functional recovery. The implementation of home physical therapy is urgently needed that can be utilized effectively without limits. But there have been rare studies on the home excercise of KTR patients, and if any, the exercise has been done as part of a routine program provided in hospitals. In addition, most studies are the ones where the continuous guidance by a physical therapist is not provided.

Therefore, this study attempted to investigate the effects of the home physical therapy under the guidance of a physical therapist by comparing discharged patients after TK with the daily living group.

\section{METHODS}

\section{Subject}

Subjects were selected among the patients hospitalized in R Hospital, S City, Gyeonggi Province, all of whom were the residents of near cities: S City, Y City, and S City. 20 subjects who have met the conditions for the object of this study were finally recruited. They were randomly categorized into the home physical therapy(10 patients) and the daily living group(10 patients). All of them were planned to be discharged after being admitted in a rehabilitation hospital after TKR and were able to independently walk at least $10 \mathrm{~m}$ without aid. The final subjects were selected among those who could communicate, had a clear consciousness, understood the purpose of this study, and agreed to participate in the research. They were examined and turned out to have no heart disease and systemic weakness.

General characteristics of the subjects of this study are shown below (Table 1).

Table 1. General characteristics of subjects

\begin{tabular}{ccc}
\hline & $\begin{array}{c}\text { Home physical therapy } \\
\text { group }(\mathrm{n}=10)\end{array}$ & $\begin{array}{c}\text { Daily living } \\
\text { group }(\mathrm{n}=10)\end{array}$ \\
\hline Age & $68.80 \pm 7.31$ & $70.40 \pm 5.56$ \\
Surgical site(Left/Right) & $4 / 6$ & $5 / 5$ \\
Height (cm) & $154.40 \pm 4.92$ & $152.40 \pm 6.78$ \\
Weight $(\mathrm{kg})$ & $63.6 \pm 8.18$ & $62.60 \pm 5.27$ \\
\hline
\end{tabular}

Home physical therapy group: Physical therapy applied after discharge

Daily living group: Home physical therapy not appled after discharge

\section{Procedure}

The subjects of this study were all discharged in four weeks after surgery. Home physical therapy using an elastic band was applied to the home physical therapy group for 4 weeks(4-8 weeks after surgery) under the guidance of a physical therapist after discharge, whereas no therapeutic intervention was provided to the daily living group.

Home physical therapy using an elastic band was conducted for 40 minutes per day, five days a week, for a total of 4 weeks. The physical therapist visited once a week and provided the guidance for the exercise program for 30 minutes. 
To the evaluation of the subjects, the pre-evaluation 1 day ago before discharge( 4 weeks after surgery) and the post-evaluation in 4 weeks after discharge( 8 weeks after surgery) were performed for both the home physical therapy group and the daily living group when they made a follow up visit as an outpatient after discharge.

\section{Methods}

\section{Home physical therapy using an elastic band}

For the home physical therapy using an elastic band, a study by Heo(18) and Yoon(19) was referred to, which consist of Park's exercise method(16) in a supine position and Kim Hyeongap's exercise method(17) in a sitting position. Especially based on the exercise program of Yoon Mee-nyeo who studied about TKR patients, the home physical therapy was constructed.
The home physical therapy was provided for 40 minutes per session, 5 days a week, a total of 4 weeks. With respect to exercise intensity, considering that the elastic band has different resistance strength by color, it was determined according to the patient's muscle. In other words, the home physical therapy was done in a range for the patient not to feel painful by determining the elastic band level at one of 13-15 levels(a little harder-hard) in rating scales of perceived exertion(RPE)(20, 21). The program consisted of warm up stretching exercises for 5 minutes and planned exercises for 30 minutes. They took a rest for about 10 seconds every exercise. A 1 minute rest was given when changing their position, and cooling down exercises were performed for 5 minutes.

The home physical therapy using an elastic band is described below(Table 2)

Table 2. Difference of cognitive function changes by exercise

\begin{tabular}{|c|c|}
\hline \multirow{6}{*}{$\begin{array}{l}\text { Warm up } \\
\text { Cooling down } \\
\text { Supine position }\end{array}$} & Stretching the ankle \\
\hline & $\begin{array}{l}\text { - Straighten toes straight ahead to stimulate the front part of the foot and leg. } \\
\text { - Tense the foot and pull it toward the body to stimulate the Achilles tendon and calf. } \\
\text { - Unfold tiptoes } 1 \text { time and pulling tiptoes } 1 \text { time, Repeat the procedure. Repeat for } 3 \text { sets (for } \\
\text { about } 5 \text { minutes) }\end{array}$ \\
\hline & Turning the ankle \\
\hline & $\begin{array}{l}\text { - Putting two laps together. Turn only two ankles } 1 \text { time in the clockwise direction and in the coun- } \\
\text { terclockwise } 1 \text { time. Repeat this operation. } \\
\text { - Perform this operation } 5 \text { times and repeat for } 3 \text { sets. }\end{array}$ \\
\hline & Stretching knee \\
\hline & $\begin{array}{l}\text { - Pull one knee toward the body and keep catching the knee for } 10 \text { seconds. } \\
\text { - Repeat this operation for } 3 \text { sets. }\end{array}$ \\
\hline \multirow{4}{*}{$\begin{array}{l}\text { Planned } \\
\text { exercises } \\
\text { Supine } \\
\text { position }\end{array}$} & Spreading and unspreading legs \\
\hline & $\begin{array}{l}\text { - Tie the elastic band on both sides of the ankle. } \\
\text { - } \text { Resist the affected forcefully; breath in slowly; spread the unaffected sideways } \\
\text { - } \text { Replace the leg open sideways, when breath out slowly. } \\
\text { - } \quad \text { Conduct this operation } 12 \text { times. } \\
\text { - } \text { Repeat the same operation for } 3 \text { sets. }\end{array}$ \\
\hline & Pulling the leg toward the body \\
\hline & $\begin{array}{l}\text { - Tie one end of the elastic band to the foot bed close to the feet. } \\
\text { - Tie the other end of the elastic band to the affected ankle } \\
\text { - Breath in slowly and pull the feet toward you. } \\
\text { - Slowly replace the leg pull toward the body, when breath out slowly. } \\
\text { - Conduct this operation } 12 \text { times. } \\
\text { - Repeat the same operation for } 3 \text { sets. }\end{array}$ \\
\hline
\end{tabular}




\begin{tabular}{ll}
\hline & Extending knee \\
\hline & - Tie one end of the elastic band to the chair leg. \\
- & Tie the other end of the elastic band to the affected ankle. \\
- & Slowly straighten the tightened knee ahead and breath in. \\
- & Replace the outstretched leg and breath in slowly. \\
- & Conduct this operation 12 times. \\
Planned & Repeat the same operation for 3 sets. \\
exercises Sitting & Straightening knee \\
position on chair & - Sit down on the bed. Put the central part of the band on the sole of the affected leg. And catch \\
& both ends by hands. \\
& (If hands move at he same time, sufficient load is not taken on the leg, so maintain the posture \\
& certainly so that hands do not move) \\
- & Straighten the leg slowly leaving the hand holding the band as it is. \\
- & Replace the straightened lag slowly and breath out. \\
- & Conduct this operation 12 times. \\
- & Repeat the same operation for 3 sets. \\
\hline
\end{tabular}

\section{Measuring Instrument}

\section{Muscle strength test}

To measure the strength of quadriceps and hamstring of the leg that underwent TRK, a small capacity system(Handheld Dynamometer) was used. This tool was named "Commander PowerTrack II Muscle Tester"(JTECH Medical, Inc. USA). It is small in size and is easy to use, so clinically useful.

With respect to the test position and the use of the small capacity system, the procedure used by Reese(22) was applied. The procedure is as follows:

To measure quadriceps femoris, the subjects were asked to place the affected leg to be tested down and to bent the hip joint $90^{\circ}$. The femoral inner part of the leg under test was fixed to facilitate measurement. The small capacity system was positioned in front of the distal calf region and the distance from this site to the surface of tibial tuberosity was recorded to maintain consistency every inspection.

The same examiner induced the maximum isometric contraction of each muscle and measured it for 3 seconds. Measurements are a numerical value represented as Newton(Newton) in a small capacity system. The average value of measurements collected 3 times was used.

\section{Walking test}

To examine the degree of gait improvement, GAIT Rite gait analysis system(CIR, Inc. USA) and the 6minutes walk test(6-MWT) were applied.

GAIT Rite gait analysis system is a measurement tool to test gait components in a reliable and objective manner(23). As gait components, gait velocity, step time, and single support were applied and measurements regarding these components were compared and analysed. For the test, after the subjects were given a 30-minute rest, the walking test was conducted. The subjects were asked to stand at $3 \mathrm{~m}$ in front of a walking board. Then, the subjects started walking by the verbal sign of the examiner. For walking, the subjects were instructed to continue walking $3 \mathrm{~m}$ across the walking board and to stop walking. The subjects were allowed to walk at the most comfortable walking speed and to maintain their speed to the end. This procedure was conducted 5 times. Measurements were obtained from 3 times of measurements, which were close to the average(4). A 5-minute break between measurements was given.

The 6-minutes walk test is a useful method in measuring exercise capacity and functional status(24). The subjects were asked to walk $30 \mathrm{~m}$ one way, marked at a 1.5 interval in the hospital corridor. They were allowed to take a rest on chair for 10 minutes and then to walk along the line for $6 \mathrm{~min}^{-}$ utes. The distance walked at a given time was displayed in meters.

\section{Data Analysis}

Data of this study were processed using the SPSS(version 18.0) program. To examine the differences before and after according to the measurement time (4 weeks before and after discharge), analysis was conducted using the paired test. And to study the differences between the groups, analysis was made 
using the independent sample t-test. The significance level $(\alpha)$ for testing the statistical significance was set at .05.

\section{RESULTS}

\section{Recovery of muscle strength of quadriceps femoris}

In changes in muscle strength of quadriceps femoris before and after study participation, the home physical therapy group showed $85.50 \pm 7.28 \mathrm{~N}$ in the pre-measurement and $113.20 \pm 10.80 \mathrm{~N}$ in post-measurement; whereas the daily living group exhibited $86.90 \pm 6.23 \mathrm{~N}$ in pre-measurement and 99 . $80 \pm 6.39 \mathrm{~N}$ in post-measurement. Both groups made a statistically significant increase or $(p<.05)$. In an strength increased width within the group, the home physical therapy group showed a higher width than the daily living group. In the comparison between groups of the home physical therapy group and the daily living group, there was a statistically significant difference(p<.01)(Table 3).

Table 3. Changes in muscle strength of quadrice femoris

\begin{tabular}{ccccc}
\hline & Pre(Mean \pm SD) & Post(Mean \pm SD) & $\mathrm{t}$ & $\mathrm{p}$ \\
\hline Home physical therapy group & $85.50 \pm 7.28$ & $113.20 \pm 10.80$ & -13.545 & $.000^{* * *}$ \\
Daily living group & $86.90 \pm 6.23$ & $99.80 \pm 6.39$ & -11.524 & $.000^{* * *}$ \\
$\mathrm{p}$ & & $.004^{* *}$ & & \\
\hline
\end{tabular}

${ }^{* *} p<.01,{ }^{* * *} p<.001$

$\mathrm{N}=$ Newton $(1 \mathrm{Newton}=1 / 9.8 \mathrm{~kg})$

\section{Recovery of muscle strength of hamstring}

In changes in muscle strength of hamstring before and after study participation, the home physical therapy group showed $70.2 \pm 5.54 \mathrm{~N}$ in the pre-measurement and $91.820 \pm 6.90 \mathrm{~N}$ in post-measurement; whereas the daily living group exhibited 68.59 \pm $9.43 \mathrm{~N}$ in pre-measurement and $76.46 \pm 10.11 \mathrm{~N}$ in post-measurement. Both groups showed a statistically significant increase or(p<.05). In an strength increase width within the group, the home physical therapy group showed a higher width than the daily living group. In the comparison between groups of the home physical therapy group and the daily living group, there was a statistically significant difference(p<.01)(Table 4).

Table 4. Changes in muscle strength of hamstring

\begin{tabular}{ccccc}
\hline & Pre(Mean \pm SD) & Post(Mean \pm SD) & $\mathrm{t}$ & $\mathrm{p}$ \\
\hline Home physical therapy group & $70.20 \pm 5.54$ & $91.82 \pm 6.90$ & -15.647 & $.000^{* * *}$ \\
Daily living group & $68.59 \pm 9.43$ & $76.46 \pm 10.11$ & -9.022 & $.000^{* * *}$ \\
$\mathrm{p}$ & & $.001^{* *}$ & & \\
\hline
\end{tabular}

${ }^{* *} \mathrm{p}<.01,{ }^{* * *} \mathrm{p}<.001$

$\mathrm{N}=$ Newton $(1$ Newton=1/9.8kg)

\section{Walking endurance test}

Changes in walking endurance before and after study participation were measured using the 6-minutes walk test. The home physical therapy group showed $266.60 \pm 15.23 \mathrm{~m}$ in pre-measurement and $291.30 \pm 22.83 \mathrm{~m}$ in the post measurement, suggesting a statistically significant increase(p<.001). There was also a statistically significant increase in the daily living group with $264.30 \pm 14.33 \mathrm{~m}$ in pre-measurement and $275.87 \pm 15.05 \mathrm{~m}$ in post-measurement $(p<.05)$. However, the endurance increase width within the group showed a higher increase in the home physical therapy group than the daily living group. In the comparison between groups of the physical therapy and the home life group, there was no statistically significant difference(Table 5). 
Table 5. Changes in walking endurance

\begin{tabular}{|c|c|c|c|c|}
\hline & Pre(Mean士SD) & Post(Mean $\pm S D)$ & $t$ & $p$ \\
\hline Home physical therapy group & $266.60 \pm 15.23$ & $291.30 \pm 22.83$ & -6.422 & $.000^{* * *}$ \\
\hline Daily living group & $264.30 \pm 14.33$ & $275.87 \pm 15.05$ & -2.632 & $.027^{*}$ \\
\hline $\mathrm{p}$ & & .094 & & \\
\hline
\end{tabular}

${ }^{*} p<.05,{ }^{* * *} p<.001$

\section{Changes in gait velocity}

In changes in gait velocity before and after study participation, the home physical therapy group showed $58.60 \pm 19.90 \mathrm{~cm} / \mathrm{sec}$ in pre-measurement and $79.59 \pm 24.83 \mathrm{~cm} / \mathrm{sec}$ in post-measurement, suggesting a statistically significant increase $(\mathrm{p}<.001)$.
However, there was a statistically significant difference $(p<.05)$ in the daily living group with $55.05 \pm$ $15.49 \mathrm{~m}$ in pre-measurement and $65.39 \pm 20.89 \mathrm{~m}$ in post-measurement. In the comparison between groups of the physical therapy and the home life group, there was no statistically significant difference(p<.05)(Table 6).

Table 6. Change in gait velocity

\begin{tabular}{ccccc}
\hline & Pre(Mean \pm SD) & Post(Mean \pm SD) & $\mathrm{t}$ & $\mathrm{p}$ \\
\hline Home physical therapy group & $58.60 \pm 19.90$ & $79.59 \pm 24.83$ & -8.458 & $.000^{* * *}$ \\
Daily living group & $55.05 \pm 15.49$ & $65.39 \pm 20.89$ & -4.311 & $.002^{* *}$ \\
$\mathrm{p}$ & & $.026^{*}$ & & \\
\hline
\end{tabular}

${ }^{*} \mathrm{p}<.05,{ }^{* *} \mathrm{p}<.01,{ }^{* * *} \mathrm{p}<.001$

\section{Changes in step time}

In changes in step time before and after study participation, the home physical therapy group showed $76 \pm 13 \mathrm{sec}$ in pre-measurement and $63 \pm 11 \mathrm{sec}$ in post-measurement, suggesting a statistically significant decrease( $p$.001). There was also a statistically significant difference(p<.01) in the daily living group with $83 . \pm 04 \mathrm{sec}$ in pre-measurement and $74 \pm 09 \mathrm{sec}$ in post-measurement. In the comparison between groups of the physical therapy and the home life group, there was no statistically significant difference(p<.05)(Table 7).

Table 7. Changes in step time

\begin{tabular}{ccccc}
\hline & Pre(Mean \pm SD) & Post(Mean \pm SD) & $\mathrm{t}$ & $\mathrm{p}$ \\
\hline Home physical therapy group & $.76 \pm .13$ & $.63 \pm .11$ & 7.285 & $.000^{* * *}$ \\
Daily living group & $.83 \pm .04$ & $.74 \pm .09$ & 3.618 & $.006^{* *}$ \\
$\mathrm{p}$ & & $.036^{*}$ & & \\
\hline
\end{tabular}

${ }^{*} p<.05,{ }^{* *} p<.01,{ }^{* * *} p<.001$

\section{Single Support}

In changes in single support before and after study participation, the home physical therapy showed $31.63 \pm 3.67 \%$ in pre-measurement and $35.04 \pm 2.61 \%$ in post-measurement, suggesting a statistically sig- nificant increase( $p$ <.01). On the other hand, the daily living group exhibited $29.60 \pm 5.24 \%$ in pre-measurement and $30.82 \pm 3.61 \%$ in post-measurement There were no statistically significant increase(p<.01)(Table 8). 
Effects of The Home Physical Therapy on Recovery of Muscle Strength and Gait for Discharged Patients Who Underwent Total Knee Replacement

Table 8. Changes in single support

\begin{tabular}{ccccc}
\hline & Pre(Mean \pm SD) & Post(Mean \pm SD) & $t$ & (unit : \%) \\
\hline Home physical therapy group & $31.63 \pm 3.67$ & $35.04 \pm 2.61$ & -3.455 & $.007^{* *}$ \\
Daily living group & $29.60 \pm 5.24$ & $30.82 \pm 3.61$ & -1.134 & .286 \\
p & & $.008^{* *}$ & & \\
\hline
\end{tabular}

${ }^{*} \mathrm{p}<.05,{ }^{* *} \mathrm{p}<.01$

\section{DISCUSSION}

The purpose of this study was to compare and analyze the effects of the presence or absence of home physical therapy on recovery of leg strength and on walking in TKR patients after discharge.

In this study, quadriceps femoris and hamstring were measured to identify leg strength. For quadriceps femoris, leg strength showed a $32.40 \%$ increase in the home physical therapy group and an $11.47 \%$ increase in the daily living group. Both groups thus exhibited a significant increase. In the comparison between groups, there was a significant difference in both groups. This implies that home physical therapy might have had a positive influence on quadriceps femoris and on hamstring.

A previous study by Han(25) reported that complex aquatic exercises from 4 to 8 weeks after KTR improved the recovery level of leg muscles with a $50.85 \%$ increase in extensor muscle and a $47.36 \%$ increase in flexor muscle. Another study by Kim(26) also revealed that the recovery level of leg muscles increased in extensor muscle, compared to prior to that study, and showed a $47.36 \%$ increase in flexor muscle. The results were found to agree with those of the study. A study by Kim(26) also reported that the application of a muscle setting program led to a significant increase in muscle recovery and put an emphasis on the importance of exercise programs for TKR patients.

In the 6 minute-walk test(6-MWT) as a walking endurance test, both the home physical therapy group and the daily living group showed no significant difference with in the group. In the comparison between groups also, there was no significant difference in both groups. However, given the short study period of 4 weeks and the significance differences within the group, the home physical therapy is considered to be more efficient(home physical therapy group $\mathrm{p}<.001$, daily living group $\mathrm{p}<.05)$. Previous studies also showed similar results to those of the study, as the exercise program applied group, which has showed the recovery of muscle recovery, exhibited better results in the 6 minute-walk test $(27,26)$.

For gait components, gait velocity, step time, and single support were evaluated using GAITRite. Benedetti et al.(28) and Lee(29) reported that elderly female patients after TKR showed slow gair velocity, longer walking cycle, and shorter step length. According to Cromwell et al.(30), when the elderly's leg muscles were weakened, the stride length was shortened, the support time of both legs became longer, and the time of one limp support became shortened. Thus, they reported that it is necessary to strengthen strength and endurance to improve gait ability(31).

In gait analysis, both the physical therapy group and the home living group showed a significant difference within the group. There was a significant difference between groups in gait velocity, step time, and single support.

Judge et al.(32) and Yoo(33) reported that strength, stretching and balance exercises after TKR improved gait velocity. In addition, a study by $\mathrm{Oh}(34)$, conducted among different subjects though, reported that knee rehabilitation for the elderly improve their gait ability, which agrees on the result of the study. Furthermore, Thomas et al.(35) reported an increase in leg muscle mass and the effect on walking ability after the application of exercises using an elastic band for 6 months 3 times a week or more for the elderly, demonstrating the importance of the exercise using an elastic band. On the other hand, Cao et al. (36) reported that gait velocity was rather decreased after applying the exercise program for 12 weeks for elderly women. Buchner et al.(37) also revealed that the application of strength training and endurance exercises for the elderly led to no or negligible effects. This is explained by the disagreement in subjects and interventions between this study and previous ones and thereby the difference in the effects on walking.

Therefore, the practice of home physical therapy 
for TKR patients after discharge was found to be more effective for walking, compared to the daily life group. In addition, since gait ability has a high correlation with balance ability(38), it appears to have a positive impact on raising the balance ability of the subjects.

\section{CONCLUSION}

In this study, 20 patients scheduled for discharge after TKR were randomized into 2 groups: the daily living group(10 patients) and the home therapy group(10 patients) where the home physical therapy using an elastic band was conducted 40 minutes per day, five days a week, for a total of 4 weeks. Both groups were compared in terms of the effects according to the presence or absence of that home physical therapy. In summary, the findings so far are as follows:

First, in the recovery level of leg muscles, both the home physical therapy group and the daily living group showed a significant difference in the recovery level of leg muscles of quadriceps femoris and hamstring. In the comparison between groups also, there was a significant difference.

Second, in walking endurance test, both the home physical therapy and the daily living group showed a significant difference within the group but no significant difference in the comparison between both groups.

Third, in gait velocity, step time, and single support for gait analysis, both the home physical therapy and the daily living group also exhibited a significant difference within the group but no significant difference in the comparison between both groups. Judging from the above results, the home physical therapy group, where the home therapy using an elastic band was applied for TKR patients after discharge, and the daily living group were compared in terms of positive changes in leg muscle and gait. The results showed positive changes in both groups. But the application of home physical therapy was found to be more effective as a result of the comparison between two groups.

And in future studies, it appears to be necessary to extend subjects and to extend the study period for more detailed and objective identification. Additionally, as an alternative to increase the satisfaction with the quality of life and the medical services in KTR patients, it may be needed to extend the care insurance approved term for KTR patients, determined to be 4 weeks, into 6-8 weeks, or to recognize home physical therapy by institutionalizing it.

\section{REFERENCES}

1. Korea National Statistical Office 2010.

2. Cho HJ, Chang CB, Jung JW, Seong SC, Kim TK. Prevalence of Radiographic Knee Osteoarthritis in Elderly Koreans. J Korean Knee Soc 2009; 21(4): 223-231.

3. Oliveria SA, Felson D.T, Reed JI, Ciril PA, Walker AM. Incidence of symptomatic hand, hip, and knee osteoarthritis among patients in a health maintenance organization. Arthritis Rheum 1995; 38(8): 1134-1141.

4. Hwang BG, Kim BJ, Bae SS. Study on the Gait Characteristics in Knee Osteoarthritis Patients with GAITRite System Analysis. The Journal of Korean Society of Physical Therapy 2004; 16(1): 113-124.

5. Kim MH. A comparatice study of TKR Patient's performance of Activities of Daily Living and Quality of Life. The Gradute School of Education Kyung Hee University. Masters Thesis 2004.

6. Health Insurance Review \& Assessment Service 2011.

7. Mizner RL, Peterson SC, Stevens J.E., Vandenborne K, Snyder-Mackler L .Early quadriceps strength loss after total knee arthroplasty. The Journal of Bone \& Joint Surgery 2005; 87(5).

8. Cho WH, Ahn HS, Kim MY, Seol ES, Lee SW, Choi JW. Pain after Total Knee Arthroplasty. Journal Of The Korea Orthopaedic Association 2006; 41(1): 129-133.

9. Stevens-Lapsley JE, Balter JE, Kohrt WM, Eckhof EG. Quadriceps and hamstrings muscle dysfunction after total knee arthroplasty. Clin Orthop Relat Res 2010; 468(9): 2460-2468.

10. Yoo MC. Latest Tendency Of Osteoarthritis Treatment. Journal of muscle and joint health 1995; 2(2): 227-229.

11. Sharma L, Dunlop DD, Cahue S, Song J, Hayes KW. Quadriceps strength and osteoarthritis progression in malaligned and lax knees. Ann Intern Med 2003; 138(8): 613-619.

12. Phillip-Page TS, Ellenbecker. The Scientific and Clinical Application of Elastic Resistance. Human Kinetics Publishers 2004. 
13. Bae SS, Nam KW, Lee KH. Isokinetic Effect of the Extensors and Flexors in Total Knee Replacement Patients. The Journal of Korean Society of Physical Therapy 2001; 13(1): 19-31.

14. Health Insurance Review \& Assessment Service 2012.

15. Choi YS, Baek SJ, Lim ES, Lee HY, Jang HJ. 2009 Health Insurance Survey of patient medical fee. National Health Insurance Health Insurance Institute 2010.

16. Park HJ. Progressive resistance exercise using elastic band of elderly diabetics blood sugar, blood lipids, effect on muscle strength and endurance. Korea University Masters thesis 2001.

17. Kim HK. The Effect of Knee Muscle Power Strengthening using Thera Band on the Balance Control Ability in the Elderly. Dankook University Masters thesis 2003.

18. Heo JJ. Effects of Muscle Strengthening Exercise Using Thera Band on Limb Function of hemiplegic Stroke Patients. The graduate school of administration Kyunghee University Masters thesis 2006.

19. Yun MN. A Study on the Effects of Exercise Program for Total Knee Arthroplasty Patients. The graduate school of administration Kyunghee University Masters thesis 2008.

20. Jeong GR, Kim SY, Park KD, Ju SB. Effects of improvement of muscle strength on exercise intensity of 1RM and RPE during muscular resistance training in the elderly women. Korean journal of physical eduaction 2010; 49(1): 535541.

21. Kim SH. Effects of Elastic-band Exercise on Physical Fitness for Activities of Daily Living, Muscle Mass and Pain in Elderly Women. Journal of coaching development 2012; 14(1): 67-77.

22. Reese NB. Muscle and sensory testing 2nd ed. New York : Elsevier Inc 2005.

23. Nelson AJ, Zwick D, Brody S. The validity of the gaitrite and the functional ambulation performance scoring system in the analysis of parkinson gait. Neuro Rehabil 2002; 12(1): 70-76.

24. Bautmans I, Lambert M, Mets T. The six-minute walk test in community dwel ing elderly: influence of health status. BMC Geriatr 2004; 4: 6 .

25. Han JH. Effectiveness of 8 weeks of application of aqua complexed exercise on lower limbs muscular strength, pain relief and balance after total knee arthroplasty. Korea University Masters thesis 2009.

26. Kim JH. Effect of Quadriceps Setting Exercise after Total Knee Arthroplasty. Department of
Physical Therapy Graduate School of Life Sciences Gatholic University of Pusan 2011.

27. Liu MQ, Anderson FC, Schwartz MH, Delp SL. Muscle contributions to support and progression over a range of walking speeds. J Biomech 2008; 41(15): 3243-3252.

28. Benedetti MG, Catani F, Bilotta T W, Marcacci M, Mariani E, Giannini S. Muscle activation pattern and gait biomechanics after total knee replacement. Clin Biomech(Bristol, Avon) 2003; 18(9): 871-876.

29. Lee YN. Biomechanical Effects of Kinesio Taping apply changes while walking TKA patients. Sam Yuk University Masters thesis 2011.

30. Cromwell RL, Newton RA, Forrest G. Influence of vision on head stabilization strategies in older adults during walking. J Gerontol A Biol Sci Med Sci 2002; 57(7): 442-448.

31. Skelton DA, Beyer N. Exercise and injury prevention in older people. Scandinavian Journal of Medicine \& Science in Sports 2003; 13(1): 77-85.

32. Judge JO, King MB, Whipple R, Clive J, Wolfson LI. Dynamic balance in older person: effects of reduced visual and proprioceptive input. J. of Gerontolohy 1993; 50(5): 363-370.

33. Yu JH. The influences of gait time and balance index to balance training in total knee replacement patients. Nam Bu University Masters thesis 2007.

34. Oh BS. The possibility of the elastic resistance exercise in knee joint rehabilitation of elders. Journal of coaching development 2006; 8(2): 3-12.

35. Tomas VS, Hageman PA. Can neuromuscular strength and function in people with dementia be rehabilitated using resistance exercise training. J. Gerontol. A. Biol. Sci. Med. Sci 2003; 58(8): 746-751.

36. Cao ZB, Maeda A, Shima N, Kurata H, Nishizono $H$. The effect of a 12-week combined exercise intervention program on physical perforance and gait kinematics in community-dwelling elderly women. J Physiol anthropol 2007; 26(3): 325-332.

37. Buchner DM, Cress ME, de Later BJ, Esselman PC, Margherita A J, Price R. The effect of strength and endurance training on gait balance, fall risk, and health services use in communityliving older adults. journals of Gerontology. Series A, Biological Sciences and Medical Sciences 1997; 52(4): 218-224.

38. Bohannon RW, Leary KM. Standing balance and function over the course of acute rehabilitation. Archives of Physical Medicine and Rehabilitation 1995; 76(11): 994-996. 